\title{
Olor, Calor, Dolor \\ NOCIÓN DE SALUD Y DE ENFERMEDAD entre los Miraña del Caquetá
}

\section{Dimitri Karadimas}

Entre intercambio y culpabilidad, la actuación Miraña frente al infortunio y a la enfermedad sale de las interpretaciones clásicas de un chamanismo umazonense para entrar en una esfera antropocentrada del universo. Esta presenlación etnográfica de nociones propias a una etnia poco conocida se basa sobre un análisis de dos mitos "terapeúticos" enunciados durante los tratamientos individuales y colectivos. La expresión particular dada por los Miraña a estos estados de desorden pasa por categorías de "olores" y "calores" que toman su dominio fuera del dominio humano.

Between exchange and blame: the behavior of the Miraña in the face of misfortune and sickness departs from the classical interpretations of Amazonian shamanism to enter into an anthropocentric sphere of the universe. This ethnographic presentation of the ideas of a little known ethnic group is based on an analysis of two "therapeutic" myths narrated during individual and collective treatments. The special expression given by the Miraña to these states of disorder pass through categories of "odors" and "heat" whose domain is outside the human domain. 
Andando con los Miraña del medio Caquetá colombiano durante varios meses en los ańos 1992 y $1993^{1}$, tuve la oportunidad de empezar con este grupo unos intercambios de ideas sobre el arte de mambear coca y de lamber el 'ambil' (una pasta de tabaco conocida como 'ampiri' en la selva peruana) y las significaciones que dan a esta práctica. Preocupado por entender la importancia reconocida a estas substancias, me dí rápidamente cuenta del entorno eminentemente 'sagrado' - según sus palabras- del acto de ingerirlas. Las primeras interpretaciones giraban, y siguen girando, alrededor de una representación altamente deificada de la relación de los humanos con unas entidades que yo llamaría, hasta cierto grado, del entorno $^{2}$. 'Ambil' y coca o, para alargar las prácticas involucradas en este estudio, bánéée íbi'é, la 'mata de tabaco' y la 'mata de coca' son los principales elementos del intercambio que ocurre entre los seres del entorno y los seres humanos, y entre estos últimos.

Esta relación ha sido subrayada por casi todos los investigadores que han trabajado en la región con grupos que utilizan estas plantas ${ }^{3}$. Uno de los tópicos sería entonces de entender el aporte idiosincrático de cada etnia a estas prácticas para poder, a un nivel regional, comparar una utilización aparentemente idéntica de estas substancias. Esta temática sería de otro trabajo, pero la elaboración de este artículo se debe entender en esa óptica.

La parte reconocida como sacralizada de las prácticas en la preparación e ingestión no excluye, por parte de los Miraña, un fuerte énfasis sobre

1 Las investigaciones han sido financiadas por una parte por el U.R.A 1026 "Ethnolinguistique amérindienne" del C.N.R.S. y por una beca del "Programme Lavosisier" Del 'Misnistère des Affaires Errangeres' del Gobierno Francés. Agradezco al Centro Colombiano de Estudios en Lenguas Aborígènes en Bogotá por su apoyo local.

2 Se debe entender aqul no solamente los seres de la naturaleza, sino también los «dueños" y otros seres imaginarios que hacen parte según los Miraña del «entorno». Con el término "entorno" quiero expresar este conjunto de condiciones naturales y culturales capaz de tener una acción sobre los organismos vivientes y las actividades humanas.

3 F. Urbina, J.A. ETcheverRi para los Huitoto. M. Guyot, C. LaRotTa, D. Karadimas para los Bora Miraña, L. Landaburu \& R. Pineda para los Andoque, S. y C. Hugh Jones para los Barasana de Vaupés P.Y. Jacopin E. Reichel M.C. Van Der Hammne para los Yukuna y otros. 
el estado de salud de cada uno. Al contrario, investigando sobre mitos enunciados durante tales prácticas, apareció la estrecha relación de la persona con la manera de sembrar, preparar, e ingerir estos productos cultivados. El propósito de este artículo es entonces de presentar la singularidad que el pensamiento Mirańa establece entre el estado de salud de cada cual y los productos cultivados. Más aún, los Miraña creen que, por una parte, el estado de salud de cada uno es el resultado de su propio cultivo en la chacra. Por otra parte, pretenden ser víctimas de varios "calores" mandados por los seres de la selva. así como de maldades procedentes de grupos vecinos. Para entender estas afirmaciones me propongo presentar rápidamente el grupo estudiado; llegar a la noción de enfermedad y de salud, y hacer una descripción de los agentes responsables de la destabilización de ésta última.

El estado de salud según los Miraña, es un enfrentamiento entre varias "fuerzas" que tratan de acaparar a la persona o a su alma por un acto de devoración. Acto que representa una restitución de un abuso de los humanos: sea entre sí, sea en contra de los animales (categoría de animales llamada iá:mé) o en contra de entidades. ${ }^{4}$ Como se ve, los Miraña no escapan al gran sistema de intercambio entre las categorías de humano y no-humano presente en el noroeste amazónico.

\section{LOS MIRANAA}

Ubicados en las riberas del río Caquetá en el departamento colombiano del Amazonas, entre La Pedrera y Araracuara, los Miraña están repartidos principalmente en tres poblamientos subiendo el río; «María Manteca", "Puerto Remanso del Tigre» y "San Francisco». Su población actual oscila entre cuatrocientos y quinientos individuos, dentro de los cuales una

Entiendo por uentidad: seres imaginarios responsables de diferentes dominios en la literatura como «dueños" o "dioses". Prefiero guarda un termino general para expresar la relación entre el tangible y el intangible. 
gran mayoría son bilingüe Miraña-Español. Los mayores de setenta años conocen solamente una palabras de castellano, y los más jóvenes solamente unas palabras de Miraña. La lengua Miraña no está clasificada. El Bora y el Muinane pertenecen a la misma familia que el Miraña, los tres idiomas aparecen más bien como variantes dialectales de una sola lengua que como tres lenguas diferentes ${ }^{5}$. Los Miraña del bajo Caquetá no hacen una nítida distinción entre los Bora y ellos mismos ya que la auto denominación piné múina 'gente del centro' (del mundo), incluye a varios grupos de filiación. Los Bora son más vinculados, según los Miraña, a grupos que venían del alto Cahuinarí frente a los que pertenecen al bajo Cahuinarí y Caquetá, que se reconocen como Miraña. La variación de denominación viene de que los últimos fueron llamados así por los Brasileños, y los primeros por sus vecinos Hitoto, que los designaban bajo la denominanción de 'bora'. Las variaciones de pronunciación dentro de estos grupos es notable, aunque hay una total intercomprensión entre ellos. La pertenencia más larga en la cual se reconocen los interesados es el grupo de filiación, más allá de esta clasificación se usa actualmente los términos de Bora y Miraña. Esta distinción es más una repartición entre grupos del alto Cahuinarí y los del Bajo Cahuinarí-Caqueta. Existe bajo las categorías de níhké muináné "gente de la punta'; y débriko maináné 'gente de la cepa', entendiendo que el Cahuinarí es el resultado de la caída del árbol cósmico, razón por la cual se habla aquí de 'cepa' y de 'punta'. Los Bora serían entonces más los grupos de la 'punta;, mientras que los Miraña los de la 'cepa'. Los Bora caracterizan también a los Miraña como áméhut muináné, 'gente del levante', esta localización está en adecuación con la desembocadura de un río aquí el Cahuinari-, que sitúa a los Bora río arriba.

\footnotetext{
5 El Muiname queda más alejado del Bora o del Miraña, que fueron hasta hace poco confundidos bajo una sola denominación.

- El término de múínáné: 'humanos', 'gente', debe ser a la base de la formación del etnónimo "Muinane». Pre Suss, 1921 p. 733, anota que Muinane significa en Huitoto, los grupos viviendo río abajo. No se puede decir si existe una correspondencia semántica entre los dos têrminos en las dos lenguas.
} 
Esta separación es más una vinculación de los grupos con sus 'lugares de nacimientos', que designa a todos una porción de territorio donde se realizó su emergencia mítica. Es según esta repartición que se designa tal grupo como de éste o de otro lugar. Casi todos los grupos son pensados como 'viniendo' del Cahuinarí. El Caquetá conoció sus grupos Miraña pero, según los interesados, éstos desaparecieron hace ya mucho tiempo, puesto que el territorio que ellos mismos reconocían se extendía hasta los raudales de Córdoba, también conocidos por los viajeros del siglo pasado como los raudales de "Ciupati' Hoy en día, los vecinos más inmediatos son los Yukuma, que se instalaron en la ribera izquierda del Caquetá río abajo de dicho raudal. También queda una maloca Yukuna en la localidad de «Santa Isabel" frente a la localidad de "San Francisco", orilla izquierda bajando el río. Dichas malocas están vinculadas por trochas al Miriti, que es el territorio de los Yukuna, donde huyeron parte de los Miraña durante la época del caucho. Los habitantes Miraña actuales del Caquetá son los descendientes de los que fueron recibidos por los Yukuna en esta época. Desde entonces, estos dos grupos tienen relaciones muy estrechas incluyendo invitaciones rituales y alianzas interétnicas.

Los otros vecinos, que también son vecinos 'tradicionales' de los Miraña son los Andoque, Huitoto, los Muinane, que comparten con los interesados una mitología y un aparto ritual similar. Los Miraña son conscientes de estas similitudes, y las expresan a través de la categoria ni:m'é muiná 'gente de umari', que traducen por 'gente de Dios' involucrando los siguiente grupos: Andoque, Bora, Huitoto, Muinane, Ocaina, Nonuya, Resigaro y a la àrómú hé 'gente de guama', grupo establecido cerca de la región del Alto Pure y con el cual hubo solamente unos contactos en los años setenta ${ }^{8}$ pero que es conocido por los Miraña como enemigos 'desde

7 Este nombre quedó al cerro que se ve más abajo de estos raudales que es una de los afloramientos más alejado geográficamente de la formación rocosa del escudo guyanense.

8 Este contacto, donde hubo un enfrentamiento que causó varios muertos, fue relatado por G. CAYCEDo en "Perdido en el Amazonas". La expedición del Ejército colombiano fue acompañada por unos Miraña. 
siempre'. Esta categoría de nt:mu'é muina 'gente de umari' se opone a la de iámé muiná 'gente de animales', que incluye a los Yukuna, Tanimuka, Matapi, Letuama, Makuna, Maku y otros de la parte norte del territorio. La partición entre estas dos categorías se hace, según los Miraña, por la manera de hacer curaciones: los que pertenecen a la primera categoría son los que dedican la coca o el tabaco a un 'espíritu' (un ser poseído por cada persona en su cuerpo), quien les ayuda a hacer la curación, mientras que la segunda categoría no se refiere a ningún 'espíritu;, sino que curan sin éste, o se refiere a espíritus de animales. Esta última categoría de espíritus es, como los vamos a ver más abajo, unas de las causas de enfermedad según los Miraña.

El lugar de investigación, llamado «Puerto Remanso del Tigre», queda a dos horas a remo arriba de la desembocadura del Cahuinarí, afluente de la ribera derecha del Caquetá. En este sitio se encuentran principalmente representantes de dos grupos de descendencia: la gente de Achiote nébámú hé, y la gente da Anaconda bòámú hè. La maloca presente en este sitio pertenece a la Gente de Anaconda. El segundo grupo presente no tiene maloca, pero vive alrededor de la primera. Cada miembro de esta "gente", que son grupos de unifiliación (en este caso no localizados) se piensa como vinculado a una maloca, que es también signo de independencia económica y un centro ceremonial.

\section{UN INTERLOCUTOR PRIVILEGIADO}

Mi informante principal, nè bá qwáhkió esto es una manera "Bora» de pronunciar.'Flor de Achiote, es el mayor del grupo de los Achiotes, aunque no el mayor de sus hermanos, ya que la madre tuvo un hijo de una alianza anterior. La historia de vida de esta persona, casi se puede decir "personaje» adentro de los Miraña, es tumultuosa y rica de enseñanzas para la comprensión de la historia reciente de este grupo. Cuando sus padres. salieron del Miriti, trataron de reinstalarse en el bajo Cahuinarí donde él nació en 1946. Fue dejado a su abuelo materno a la edad de diez años para 




Una fuente de información inagotable:

Flor de Achiote (Nébà̀ Gwáhkd). 
recibir una enseñanza chamanística màmáyßẹ djửßábú hasta la edad de dieciocho años cuando empezó a perder la vista. Al mismo tiempo murió el abuelo sin poder terminar, según relata, la enseñanza chamanística. La muerte de su abuelo fue interpretada como el resultado de una 'maldad' venida de un isúkóbé 'brujo', la misma que afectó también su vista. Según su relato, empezó desde ese momento una vida de errante, que lo llevó hasta el internado de La Pedrera, para ser catequista. Regresó más tarde donde su madre que se había instalado con sus otros hijos a Puerto Remanso del Tigre, conocido antes como Puerto Miraña ${ }^{9}$. Fue allá donde se quedó como cantante (unos de los papeles rituales de los Miraña), ya que no podía hacer curaciones. Trabajó en los ańos setenta con la antropóloga francesa Mirelle Guyot, luego con el misionero de los «New Tribes Mission» Wayne Smith, con el cual sigue trabajando, y al final de los años ochenta con la lingüista R.A Escobar Pinzón, donde lo conocí.

Su narración de la tradición Miraña queda muy marcada por connotaciones bíblicas, más que todo en las traducciones de algunos conceptos. Por otra parte, él es unas de las fuentes de información más segura ya que no utiliza los mitos con fines terapeuticos, que es la función más marcada de estas narraciones. Los otros terapeutas no podrían contar estos mitos a otros investigadores porque los Miraña piensan que la potencia curativa está en el mito. Contar un mito, es curar. Del mismo modo, los que curan o cuentan, siempre están en una relación de intercambio de coca y tabaco que es la contraparte de la curación o de la narración. Los mitos Miraña transcritos en la literatura, principalmente los recogidos por M. Guyot, lo fueron con este mismo informante. La etnobotánica Constansa La Rotta presenta igualmente unos mitos que les fueron contados por informantes de la comunidad de San Francisco, pero ninguno de estos mitos figuran con la traducción de los nombres de las entidades involucradas. Los nombres de los agentes eficientes, las entidades, quedan en una relación oculta

9 No se sabe si se trata del mismo "Porto Miranhan que está señalado por Spix \& Martius en 1820 sobre el Japurá. 
al lector. Esta situación puede ser el resultado de una falta de voluntad de traducción de parte del autor, pero más bien es una manera para el narrador de preservar su relacion con la entidad involucrada.

La principal dificultad en las investigaciones con los Miraña es ésta. Los mitos son actos que necesitan contraparte de coca y tabaco para que la entidad llamada se nutra de estos 'alimentos'. Como los investigadores no tiene cultivo propio de coca o de tabaco, quedan afuera del intercambio.

Mi informante a pesar de tener la información de chamán y conocer los mitos, no está en la situación de un curandero. No tuvo la oportunidad, según él, de terminar su formación hasta llegar a curar. No está, entonces, bajo el peligro de perder el apoyo de sus entidades protectoras. El mito relacionado al tratamiento de un paciente mordido por una culebra, por ejemplo, aunque conocido, no me fue contado por el hecho que si se hacia fuera de una curación, podría llamar la atención del espíritu encargado i:nime ná: ßéne 'espíritu de culebras', y llevaría a un encuentro, los días siguientes o más tarde, con unas de estas serpientes. El encuentro podría ser con él mismo, con la persona que escuchó, o con algunos de los familiares de estos dos.

La contraparte mía, aunque no podía proceder obviamente de un cocal personal, ha sido coca y tabaco sembrados por otros. La manera de llegar a ésto fue colocarme en la posición de ayudante joven que participa en la colecta de las hojas en el cocal para tostarlas. Esta posición, es también la de los jóvenes que están en proceso de aprendizaje chamanístico, aunque este proceso está 'pagado' en coca y tabaco por el propio padre del joven, puesto que el aprendizaje empieza lo más temprano que se puede (alrededor de los diez años). La contraparte de esta 'ayuda', consiste en recibir una parte de la producción diaria de la coca en polvo. Dicha parte me permitía participar en las reuniones nocturnas donde se contaban las narraciones, como también me permitía que me contaran unos de estos mitos, para poder trabajar de día con mi informante. 


\section{ESTADO DE SALUD Y NOCIÓN DE ENFERMEDAD ${ }^{10}$}

No todos los mitos están relatados para restablecer un estado que se podría entender como 'salud' para nosotros, pero síllevan un aspecto terapéutico. El concepto mismo de salud depende de un estado más general de la persona que, al mismo tiempo, está vinculado al resto de su familia que puede influir sobre él. El estado de integridad personal está vinculado a una esencia más amplia involucrando a todos los 'parientes'. Esta categoría presupone que una misma esencia está compartida por todos los miembros de un i:éte, noción que se podría llamar, en términos antropológicos, la consanguinidad. Pero, además de los humanos, este término involucra unas especies vegetales y animales que hacen también parte del tiéte de uno. A nivel estrictamente humano, los que se pueden nombrar haciendo parte del liéte de uno son los parientes de ascendencia y descendencia, excluyendo la relación de afinidad. A estas personas se añaden especies vegetales y animales, que están en esta misma relación de consanguinidad con el hé de cada uno. Este término designa esta parte del t:éte estrictamente agnática que define la posición social de cada uno según su orden de nacimiento. El hé es entonces el grupo de unifiliación patrilinear, mientras que el íéte lleva el aspecto de consanguinidad. Los Miraña traducen la primera noción por "gente de", que distinguen del término muinà refiriéndose más a la noción de ser humano pero que recibe la misma traducción de "gente de", puesto que el castellano local no distingue terminológicamente las dos nociones. El segundo término, t:été esta traducido por "familia» o "parentescon. Para no entrar en cuestiones de parentesco por no ser el tema de este articulo, señalaremos solamente que esta última noción presupone una consustancialidad entre los que se reconocen como haciendo parte de un mismo l:éte. Es esta consustancialidad que vincula una persona a otras, y que puede hacer influir el estado de salud de cada uno de ellos según el estado de los otros. 
La noción de salud personal es entonces una cuestión supra individual pero no extendida a toda la sociedad. Las manifestaciones de estas creencias se encuentran principalmente cuando el curandero, después de un enfermedad, restablece la integridad de un paciente, las prohibiciones alimenticias propias a cada tratamiento son muchas veces extendidas a los miembros del tété del paciente. Puesto que los involucrados pueden ser numerosos, y que los Miraña piensan estar siempre bajo peligros chamanisticos, no quedan muchos, en su sitio, que escapen a alguna restricción.

\section{CALORES Y SERES PROTECTORES DE LOS ANIMALES}

Los procesos fisiológicos de la enfermedad son, según los Miraña, 'calores' kúbúgwá que aniquilan la 'fuerza' de la sangre túú, por 'quemaduras'. La enfermedad es el poder destructor contenido en los 'calores' mandados por varias entidades (ver más abajo) que 'queman' la sangre de las personas. Se piensa que las quemaduras destruyen el principio vital contenido en la sangre. El estado del cuerpo sano no está pensado como 'frío', sino al contrario como un mantenimiento de su nivel isotérmico. Cualquier acto o pensamiento que conlleva a una excitación está entendido como atrayendo las entidades dañinas que toman posesión de estos lugares corporales 'calientes'. Antes de un ritual o de un trabajo colectivo, el trabajo del chamán es de tsíkóbarál 'enfriar' las entidades alimentándolas de coca y tabaco. Esta nutrición, que es también para los Miraña un acto de reconocimiento de las entidades involucradas, tiene como finalidad hacerlas participar en el acto colectivo. La producción de 'calores', el tumulto de un ritual, la efervescencia al momento de abrir una chacra, los intercambios de palabras en el mambiadero de coca, serán desviadas de la producción de calores en el cuerpo para tener su expresión en el acto que se realiza. El éxito de estas actividades no es tanto el logro de haberlas cumplidas, sin que se cumpliera sin 'calor'. Los usos de ciertas plantas, principalmente Pteridophytas, son para curaciones individuales como para tratamientos colectivos, rituales y 'mingas'. Estas plantas, que se preparan en infusión para tratamiento individual, se emplean también como repulsivos en las reunio- 
nes colectivas. Se recogen en cantidades y, antes de la llegada de los bailadores viniendo con cacería, se azota con ellas el lugar donde se va a realizar el ritual. Al entrar en esta área, se va a cambiar el olor del ambiente, y así tantos los participantes como las entidades que se reunieron por la excitación de los humanos, se calmarán. Muchas veces esta fase toma la forma de un paso inaugural del ritual, que se realiza bailando. Algunas entidades estrictamente dañinas se verán en la obligación de huir, ya que se dice que no pueden soportar el olor de estas plantas. El olor pàkúkrú, es el medio por el cual las enfermedades se propagan. Algunos de los animales tiene un 'olor' propio, asociado a un poder destructor ${ }^{11}$. Los invitados a un ritual, que tiene la obligación de traer cacería, se ven muchas veces acusados de llevar enfermedades por no haber 'curado' su cacería antes de dejarla entrar en la maloca. Estos olores, materializados por el almizcle -que lleva el mismo nombre de pàku'ku' 'olor'-son responsables, según los Miraña de estados de debilidad profunda, de nauseas y, sobre todo, de dolores de cabeza. Se puede encontrar estos olores en el monte cuando por ejemplo uno ha matado algún animal que lleva estas glándulas. El chamuscar un animal de pelo, más que todo los micos, está concebido como liberando y al mismo tiempo aniquilando estos olores. La consecuencia directa de esta creencia es la bipartición del universo de las presas del monte. Existen animales con pàkúkú y animales que no tienen esta substancia. Los animales que llevan esta substancia son considerados como peligrosos, transmitiendo enfermedades, y dispuestos a vengarse de la punzada efectuada por los cazadores. El peligro afecta principalmente a los niños del cazador, y a los que comen la carne del animal. Los iáme náßéné espíritus de los animales' persiguen entonces la descendencia de los humanos para llevarla abajo de la tierra, donde tiene sus malocas, $\mathrm{y}$ transformarla en sus crias para compensar la pérdida.

1 Así el caso Yagua; según J.P. Chaumeil (1985, p.219): "L'odeur forte que dégage un animal para exemple en fera un efaiseur de maladien. 


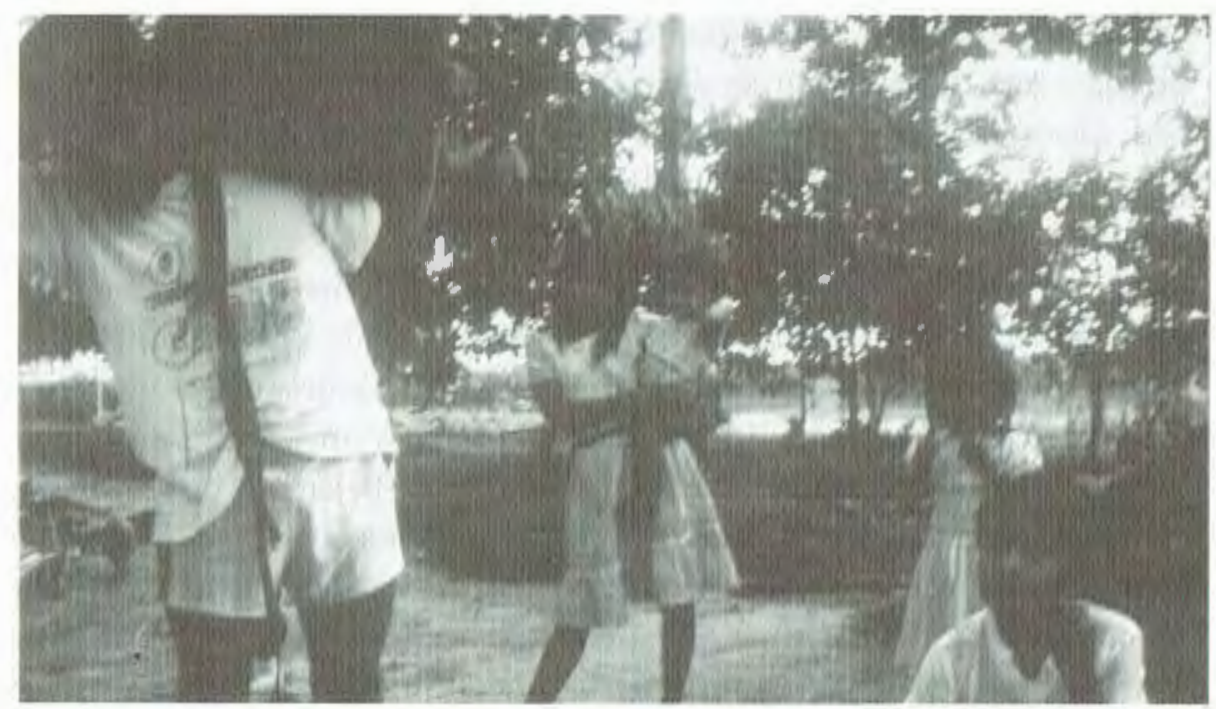

Llegada de un vector de enfermedad: un animal con 'olor'

La segunda clase de animales, los que no tienen 'olores' es decir los que no tienen almizcle, son principalmente las aves y algunos roedores que viven cerca de la habitación o en la chacra. Estos animales pueden ser consumidos sin gran peligro, porque no traen peligros por sí mismos. La dicotomía en el reino animal - excluyendo a los peces - va sin embargo más allá de esta presencia o ausencia de pakúkú. La primera categoría está pensada como una independencia propia frente a los humanos y, además, está en casi relación de enemistad completa con ellos. La segunda categoría está pensada como compuesta de seres creados por especies vegetales cultivadas por el creador. Estas especies son las mismas que las cultivadas en las chacras de los humanos, a diferencia que son de esencia divina. Es decir que lo que se consume en este caso son plantas del jardín del creador que se presentan a los humanos bajo forma animal. La entidad responsable de esta clase de animales es el creador mismo. Eso no quiere decir que el peligro esté completamente ausente cuando se consumen estos animales. Los Miraña dicen que el creador puede castigarlos mandándoles unos representantes de estas especies no hechos -con plantas con la parte comestible de estas plantas- sino con barro. La ingestión de estos animales es también causa de 
enfermedades, aunque no esté marcada terminológicamente, y no corresponda a una categoría nítida de enfermedad. Los efectos sobre la persona son: aliento nauseabundo, nauseas y dolores de estómago. Este castigo no lleva hasta la muerte, puesto que la muerte es un acto de devoración.

Son entonces los 'olores' que producen los 'calores' causa de dolores. La manera de luchar contra estos 'calores' es tratar de 'enfriarlos'. Para lograrlo se utiliza unas plantas, no cultivadas en la mayoría, a las cuales se le atribuye propiedades enfriadoras. La más usada es un helecho nombrado támidje. Adiantum tomentosum. Se puede tomar el ejemplo de esta planta para mostrar como los Miraña piensan el uso de estas plantas enfriadoras. Cuando un djúßábe' "curador' decide curar con esta planta para alejar calores o calmarlos, tiene que 'mambiar coca' dedicándola a me pißéne' 'nuestro Creador', para que este ser primordial pueda influir sobre mé tst kòbárá támidjé kò itsúbà 'la garza de barra de Adiantum tomentosum de nuestro enfriamiento', quien es la entidad encargada de esta planta. Esta garza va, a su turno, a mandar a los ú ónémú, unos seres protectores del monte (pensados como guerreros al servicio de una entidad de un nivel jerárquico más alto, traducido por 'curupira' según mi informante) que van a pelear contra los íamé ú ónémú, los ú onémú de los animales que están causando los dolores en el cuerpo del paciente, aunque no están presentes en su cuerpo. Del éxito de esta pelea depende el éxito de la curación. Estos seres están presentes cuando se mata a un animal, recogen la sangre caída sobre unas hojas para reconstruir el animal muerto (el término está formado por el substantivo ứo-: 'hoja caída', né: sufijo de agente y mú: sufijo plural, se podría traducir por algo como los 'hojeros', 'los de las hojas caídas'). Recogen las hojas con sangre y las envuelven en una hoja de platanillo ${ }^{12}$ llamada lámé áykéßé íhikó 'platanillo de reviviscencia de los animales'. Los Miraña piensan después que estos seres soplan tabaco para que se reconstituya la carne del animal, soplan otra vez y se anima, luego lo sacan de la envoltura, so-

12 Phenakospermum guianensis. 
plan por última vez con humo para que tenga pelos. En este momento, dicen los Miraña, los humanos están comiendo la carne del animal mientras los ú ónémú lo están reconstruyendo. Por esta razón se debe siempre dejar la sangre del animal en el monte. Otros cazadores dicen que hay que dejar la cabeza y las entrañas de la presa para los úónémú. Los cazadores que no respetan esta prescripción, principalmente por acto de venganza en contra de los animales que mandan enfermedades, se enfrentan a la ira de estos seres protectores.

Los.Miraña no colocan todas estas entidades en un mismo nivel jerárquico, los úónémú no son interlocutores directos, no se puede negociar directamente con ellos, puesto que viven bajo la responsabilidad de una garza que puede ser entendida como el áyßébúbên de ellos: su 'capitán'. Existen tantos úónémú diferentes como garzas encargas. Varios elementos como árboles, plantas lugares... tiene garzas; existen entonces tantos u'ónémú equivalentes. Estos árboles, plantas y lugares están pensados como iñúhine, cada uno es un 'mundo' o una 'tierra; espiritual. Este concepto de 'mundo' no significa para los Miraña que estén hechos a la imagen de esta tierra: teniendo cielo, monte y ríos - ya éstos son otros mundos para sí mismo sino más bien como integrando unos seres organizados según el modelo de la sociedad de los humanos.

\section{PLANTAS Y DUENOS DE LA CURACIÓN}

La correspondencia exacta es más bien que las plantas de curaciones son como tantas malocas para los 'dueños' que son responsables de éstas. Cada planta curativa tiene así, presupuestamente, una pareja de dueños: masculino y femenino, a veces una pareja de hermanos, quienes, de acuer-

Más bien, la garza toma en la mitologla y en las curaciones, el papel del hijo mayor, dejando al "umari" la posición de "capitán". Los personajes, hijo y padre, llevan responsabilidades complementarias. El hijo mayor con relación al exterior, y el padre siendo responsable de la maloca. 
do con el modelo de los dueños de una maloca, defienden el uso de las plantas, se les debe ofrecer coca, tabaco y caldo de almidón de yuca. Se debe ofrecer estos productos a los dueños de malocas cuando se les visita para pedirles una ayuda de trabajo o, como en las primeras décadas del siglo, una ayuda en conflictos entre malocas. Esta relación está pensada como una relación de subordinación. Ocurre muchas veces que se conoce solamente a la entidad masculina o a la femenina de esta pareja. Existen también plantas que son solamente la materialización de unas de ellas, el otro elemento de la pareja esta materializado por otra planta. En oposición completa con esta concepción, se conoce también algunas plantas curativas que no poseen 'dueños', y que curan 'por sí mismo'. Por ejemplo una planta que lleva el mismo nombre de Andiantum tomentosum : támidjé, pero que está considerada como el «támídjé pequeño" y que está clasificada como Lindsaea lancea, al contrario de la otra planta, no tienen ningún dueño aunque lleva el mismo nombre. Estas plantas son, según los interesados como las 'drogas de los blancos'. Entran en automedicaciones que no necesitan la presencia del especialista. Eso demuestra que su trabajo principal es el acto de permitir la comunicación con las entidades responsables de las plantas. El djúbábé es principalmente un intermediario, no está pensado como una persona que cura por sí mismo aunque el término que lo caracterice provenga de la palabra para curación.

Se las encuentra en algunos mitos, esas entidades a las cuales los 'vivientes' piden ayuda. El mito, como lo apunté más arriba, es el acto curativo mismo, puesto que es el principio curativo en el sentido de eficiencia mayor sobre la causa de la enfermedad.

El mito siguiente es una de las gestas de la larga 'historia' del héroe cultural djuibtsiri "el soplador de cerbatana’ o 'el Flechador', quien, después de muchas peripecias, llega a enfrentarse con unos "cucarrónes pedómanos" ${ }^{14}$. Esta parte del mito está también conocida como el origen de las enfermedades.

14. Este mito me fue contado por nébá gwdhké «Flor de achiote» en castellano. Los nombres de las entidades están en Miraña, traducidos por el informante. 
1. «Dicen que, en aquellos tiempos, en que el Flechador, por curiosidad andaba por el mundo haciendo daño a todos los vivientes.... Y al fin porque después de eso, se le quitó todo el daño que él estaba haciendo - él llegó donde los hijos de bá:bábü t5 $^{\text {. }}$

2. El Flechador preguntó: "para donde se fueron su papá y su mama?» - "Se fueron al monte para busca cacería" - "Y qué clase de cacería mata su papá?" - «Los micos voladores ${ }^{16 !}$ "Y el Flechador pregunto: "Con qué matan estos micos’» - "Con el pedo!» Y él preguntó: "Cómo ellos matan con pedo?» - "Como un echa pedo!" respondieron los hijos - "Pero quién mata con pedo?" - «Sí así ellos matan siempre!" Y el Flechador dijo: "Eso es una mentira de ustedes, muchas veces uno echa pedo, pero nadie se muere!" y siguieron discutiendo así.

3. El Flechador les dijo: "A ver, hagan un pedo, para que yo pueda ver!" y respondieron: «No, cuidado que nos vamos a quemar! No podemos vivir así!» - "Pero quién se quema con pedo?» Y siguieron discutiendo así hasta que el Flechador dijo: "Si se prende, yo voy a apagarlo!".

4. Yentonces, de tanto rogarle, el muchachito, el menor, comenzó a echar un pedo, y disparó, encendió, salió una llama. Y entonces el Flechador garrotió, el mas echó otro pedo y otro...... La llama se regó.

5. Y entonces el Flechador dejó de apagar y se corrió . Y mientras eso, los padres estaban cerca, llegando de cacería. Y los niños llamaron al papá: «Papá, papá, el curioso, el flechador, nos mandó a echar pedos, y nosotros echamos pedos y se prendió candela!" Y respondieron los padres: "dónde está él?» - «Ya huyó!» Y entonces el padre comenzó también a echar pedos, y la mamá también. así ellos rezaban antes de echar pedos: gwáñtrút! gwáñirú ! gwáñtrú t... táby! $]^{17}$ entonces, atrás

15 Especie no identificada. Escarabajo de color verde brillante que produce una orina (?) que, al contacto con la piel produce quemaduras.

16 Pithecias sp. Una metáfora mítica. El mito presenta una inversión de los actores: los animales y las entidades toman imagen humana mientras que los humanos se vuelven animales.

17 Fórmulas onomatopéyicas del sonido de los pedos que están bajando en las tripas de los cucarrones 
de Flechador la candela le perseguía, tumbando monte, quemando animales, no perdonaba a nada.

6. Entonces el Flechador ya no se aguantaba, y el se quejó a una $\ell_{\text {.ñúhí }}$ tsíkóbárá mé gwá 'mujer de enfriamiento de la tierra; diciendo: «tádjé tádjé, mépî̉é tsí kógwá ámuihiti mé: gwá" 'abuela, abuela mujer tsí kogwá ámúhi (Peperomia sp) de enfriamiento de nuestra creación sálvame de la candela de bábáhú que ya no me va a perdonar! " "Bueno nieto, venga por acá, yo estoy aquí!» $\mathrm{Y}$ así el Flechador se apoderó de ella. Pero se acercó el calor de la candela. Entonces ella dijo: «Nieto, ya no vivimos! sálgase rápido, váyase rápido"19! «Y él se corrió, y la candela atrás de él.

7. Y dijo :mabuela, abuela, mèpißé tsikobbára dórópíhi mé:gwá 'mujer de dorópihi i ${ }^{20} \mathrm{de}$ enfriamiento de nuestra creación' sálvame! Que esta candela de bá:bábú no me va a perdonar» y Ella dijo : «bueno nieto, venga acá, yo estoy aquí!» y ella lo recibió. Pero ya se acercó el calor de la candela y ella dijo: «nieto, ya no vivimos, váyase rápido!» y el Flechador salió corriendo y la candela atrás de él, persiguiéndole.

8. Lo mismo con las siguientes:

* mèpîse tsikòbárà ágwá èbáe mé:gwà 'La mujer del agua de los troncos de enfriamiento de nuestra creación.

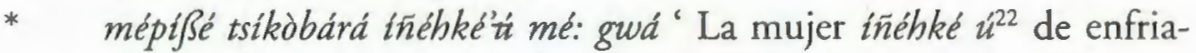
miento de nuestra creación'.

* ' 'la mujer náßé:múthké 'ita de enfriamiento de nuestra creación.'

18 Peperomia sp. fam. Piperaceae.

19 De la maloca de esta mujer.

20 Trichomanes ankresii. fam Pteridophytas

21 Agua que queda en los palos podridos, se recoge exprimiendo la masa podrida del tronco. Se considera como agua limpia

22 Bignoniceae sp 'Bejuco de canangucho'. Este bejuco da agua cuando está cortado. Según el narrador, esta 'mujer', puede ser 'buena' o 'mala' según que el que la llama sabe o no la 'historia'.

23 Dolicarpus multiflorus. fam. Dilleniaceae. Traducción literal 'bejuco de los espíritus'. Este bejuco, según el narrador, no se quemó bien, por eso quedó negro en la cáscara. Cortándolo deja salir una agua con la cual se cura 
'la mujer tsíyóróké' to de enfriamiento de nuestra creación' 'la mujer inityúba' $z^{25}$ de enfriamiento de nuestra creación. 'la mujer màtsákébke ử de enfriamiento de nuestra creación.' 'la mujer nißrigwàymù 'ü ${ }^{7}$ de enfriamiento de nuestra creación' 'la mujer ìhbikdbá ${ }^{28}$ de enfriamiento de nuestra creación. 'la mujer ná:mégwábké ' $\imath^{29}$ de enfriamiento de nuestra creación.' Y también con las dos hermanas ${ }^{30}$.

* ' 'la mujer tímá:kàbrà ${ }^{31}$ de enfriamiento de nuestra creación.'

* 'la mujer nákóóbit ${ }^{32}$ de enfriamiento de nuestra creación'

9. Entonces éstas le dijeron: «Aquí! Aquí estamos nosotras. Nosotras sí, no tenemos miedo de ninguna candela!n Entonces ellas dos lo recibieron y lo echaron en 'la pieza de enfriamiento de hierba buena ${ }^{33} \mathrm{de}$ ellas dos ${ }^{34}$.

10. Entonces, la candela de bá:bábrá viene contra ellas, y ellas mojaron con el agua de 'hierba buena' de la creación de ellas. $Y$ así se apagó la

Id? Bejuco liberando un agua cuando se corta. Sirve además para envolver las cerbatanas y los bordes de cernedores.

25 Leg, Fabiodecae indet 1. Traducción literal «Bejuco de iguana», produce agua el seccionarlo.

26 id? "Bejuco de mani», produce agua al seccionar.

${ }_{27}$ Pseudocannarus macriphylla. Lit. "Bejuco de venado".

28 Placanillo. cf. supra.

29 Lonchocarpus sp. «Bejuco dulce».

30 Se dice que son hermanas porque vivían en el mismo sitio, en la misma maloca. Accualmente, según los Miraña, la primera vive en trono de un palo, y la segunda es un helecho epífilo, LAROTTA; p. 69).

3! Antrophyum cajanense o Polyphyum decumanum Fam. Pteridophytas según LARoTTA, p. 64, esta última especie (Polypodium decumanum) es semiepifita, lo que corresponde a la descripción (ver nota anterior).

Trichomanes pinati, Fam. Pteridophytas. «hierba de camarones». Esta especie tiene unas micro-ráces que tienen la forma de antenas de camarones. Se encuentran cerca de quebradones donde hay camarones de agua dulce. Más allá en el mito del soplador, cuando él está sufriendo con las lanzas de los peces heridos en sus articulaciones, va a encontrar unas mujeres camarones que les van a 'soplar' sobre sus heridas para aliviar el dolor. La conexión está seguramente con esta planta, los camarones prefiguran la versión aquética de ésta. Cf. nota anterior. Esta especie lleva localmente el nombre de «hierba buena».

Se hace referencia a las piezas de la maloca, donde huyó el flechador 
candela, no quedó ninguna llama. Ahí sí, dijo el Flechador: «Abuelas, ustedes, por fin, me salvaron. Había muchas abuelas mías de enfriamiento, pero ninguna era capaz de apagar la candela de los bá:bábú. Como pudieron ustedes apagar unas llamas tan grandes!» «Si nieto, con nosotras, nadie puede. En favor de usted nosotras apagamos.» Y entonces el Flechador quedó libre. El dijo: «Ahora sí, yo no tengo miedo de nadie, porque mis dos abuelas me defendieron del peligro de la candela.

11. Pero en eso se levantaron:

* iñábi kúbrígwá náßém iz 'la candela de los espíritus del mundo’

* nímiż émú k'úhrúgwànè 'las candelas de los dioses' 35

* iamé pi:Séné kíuh rírgwànè 'las candelas de la creación de los animales'

12. Eso también trató de hacerlo daño. Pero estas dos mujeres la apagaron, así como hicieron con las otras candelas. Ahí sí quedó libre. Y el flechador sintió un reconocimiento para ellas: «Abuelas, yo creo que en el mundo no hay nadie como ustedes. Así será que ustedes dos, con la gente nueva, les van a servir frente a esta clase de peligros.» «Si miento, nosotras sí, las personas que se quejan a nosotras no les va a pasar nada, porque con nosotras nadie puede».

13. Por eso es que nuestros antiguos se apoderaron del espíritu de estas dos mujeres, dueñas de esta hierba buena».

Este mito, que produce una hilaridad general al principio y que termina con la seriedad de los participantes al 'mambiadero', relata casi literalmente las concepciones Miraña de la enfermedad. Empezando con una evocación de los 'olores' - aquí los pedos-, se relacionan directamente con los 'calores' que están produciendo. Las 'llamas' que están quemando el 'mundo' son obviamente comparables a las que están quemando el propio

35 Nimúé: "guacure» o "umari», Poraqueiba sericea. Esta mata, que produce unos frutos aceitosos, es, según los Miraña, una de las cinco materializaciones del demiurgo en esta tierra. Recibe, por su versión mítica, la traducción de "Dios», pero se puede entender como una deificación de personajes míticos que llevan el papel de personaje mayor en la mitología Mirafia: son presentados como padres de las tantas 'garzas' que existen en los 'mundos'. 
cuerpo del paciente. Esta relación puede también entenderse como una visión cósmica del cuerpo, dentro de la cual el pensamiento del narrador se mueve a la imagen del héroe mítico huyendo de las llamas de los cucarrones.

La evocación de los micos voladores -caceria de los cucarrones- es decir los humanos, puesto que los micos han sido la primera humanidad para los Miraña, levanta la última duda frente a la identidad de las víctimas. Cacería humana contra dispensador de calores, enfermedad como acto antropófago, tales son las metáforas del principio del mito. Pero el acto provocativo del héroe, pidiendo que le toque ser cacería, por incredulidad frente al orden de las cosas, es también una presentación de la vanidad de los humanos, quienes, según los Miraña, piensan escaparse de sus propias provocaciones y abusos frente a las entidades. Al final siempre caen bajo la venganza de los animales.

La salvación del héroe, debido a sus 'abuelas', es una versión' 'medicalizada' de un mito Arawak común en el área amazónica y conocido como el mito de Poronominaré. C. Lévi-Strauss, analiza una variante de esta parte del mito de la manera siguiente: "(...) Le héros réussit á s'enfuir par l'àme de sa sarbacane de la demeure d'un mari trompé qui tente de le tuer à coups de pets explosifs: en somme, un tauyau le sauve d'un autre tuyau" (1985, p. 210). Esta versión en la cual el héroe se escapa de los pedos calientes de los cucarrones, clavando su cerbatana y huyendo a través de ella a otro mundo, existe también en la mitología Miraña. Pero el mito presentado aquí no hace referencia al ordenamiento cósmico, y a la pelea de los astros dando emergencia los 'artes mayores', como las llama Lévi-Strauss, que son la alfarería y la textilería; temas tratados por estas series de mitos según este autor. Mas bién estamos frente a un mito que hace del acto de curación, un tema mitológico más amplio donde están presentes elementos de narraciones aptos a reflejar las concepciones del equilibrio de las fuerzas entre víctimas y abusadores.

En vez de tener un conducto - la cerbatana- que lo lleva a 'otro mundo', tenemos varios mundos - las malocas de las abuelas - que representan 
salvaciones horizontales en vez de la salvación vertical encarnada por la cerbatana clavada. Las dos versiones no son mutuamente exclusivas, sino que representan dos niveles de aplicación diferentes. El nivel presentado aquí, que es el nivel de utilización terapeutico - el que nos interesa, permite la creación de una jerarquización de los 'mundos' de salvaciones. Esta jerarquización, representando las diferentes opciones a la disposición del curandero, está pensada como una sucesión de malocas. De un cierto modo, lo que el mito presenta es el camino - en pensamiento - que lleva de una planta a otra.

Camino y cerbatana están en relación paralela, puesto que los dos están concebidos como contenientes abiertos por ambos lados, aunque el camino se debe abrir en todo su curso- el conocimiento que lleva a una planta a otra - mientras que la cerbatana es, en la otra versión, el instrumento que abre su propio punto de pasaje a mundos superpuestos. Tenemos aquí una metaforización del acto de aprendizaje chamanístico, ausente en la versión de la huida vertical del héroe.

En primer lugar se puede interpretar la enunciación sucesiva de las plantas que van a tener un poder curativo, gracias a la intervención de sus dueñas, como relacionando el héroe del mito con el paciente en tratamiento. En vez de tener un héroe huyendo de maloca en maloca, va a llegar al paciente una sucesión de plantas con sus dueñas. A este nivel de interpretación, se podría decir entonces que el paciente de la curación es el héroe del mito. Sería olvidar la forma narrativa que presenta la huida del héroe no como una intrusión voluntaria en las malocas, sino como una súplica en frente de la cual se declaran las dueñas de estas malocas. Así como lo he presentado más arriba, se debe más bien interpretar esta forma narrativa como mostrando el héroe a la manera de un 'revelador' de las malocas -las plantas- que existen contra esta enfermedad. El héroe mítico es más bien el personaje intermediario entre las llamas y las malocas supuestamente salvadoras. Entre el mito y el acto curativo, el paciente es ausente. Más aún, el mito aniquila la existencia del paciente como persona en su relato. El paciente no está presente como personaje en el mito. Tenemos entonces 
solamente tres personificaciones: los cucarrones y sus llamas -los agentes de la enfermedad y su materialización dañina-, el soplador de cerbatana, héroe mítico -el djúßábè o curandero- y las malocas y sus dueñas -las diferentes plantas que pueden entrar individualmente en el tratamiento. Esta ausencia del paciente se encuentra también en la primera fase del tratamiento. El chamán puede realizar su mediación con las dueñas de las plantas fuera de la presencia del paciente. Las dueñas están para ayudarle a reconocer quienes son los agentes patógenos. La posición de intermediario del curandero ubica al paciente a un nivel de anterioridad. La mediación no se realiza entre el paciente y las dueñas de las plantas, sino entre estas últimas y los agentes patógenos. Mirando al curandero en el acto terapeutico, se encuentra aislado, 'soplando' sobre una substancia, muchas veces unas de las 'aguas' presentadas en el mito. Este primer 'soplo' que se ve, es el mito que el curandero se está contando, y que sigue el ritmo de la narración. El 'soplo' que está pensando como llegando sobre el agua es la narración. En este momento, no se puede interrumpir al curandero. Tampoco se puede dejar tocar por mano ajena el agua después de haber narrado el mito. Los Miraña expresan esta relación en el castellano local diciendo que ella está 'rezada', está ibádjènéi (de ibádje 'cuento o relato' o 'contar' en su forma verbalizada). Literalmente, se insufla un poder curativo a una substancia 'profana', puesto que después de eso no se puede alterar su pureza que, en cierto modo, la lleva al nivel de 'sagrado' (es interesante notar que, para expresar esta relación, los Miraña tomaron una palabra castellana relacionada con las prácticas religiosas).

\section{LAS TRES 'LLAMAS'}

Paralelamente a la personificación del agente patógeno mítico están presentadas, al final del mito, las tres clases de 'fuegos' reconocidas por la cultura Miraña. La primera parte del mito relata solamente la emergencia de la enfermedad. Los pedos del cucarrón son, como hemos visto, la metáfora mítica para presentar la enfermedad como noción general. Los responsables de esas enfermedades son distribuidos según tres categorías: iñúbi 
kúhrúgwà náßémú, 'la candela de los espíritus del mundo'; nì:múèmút kúhrúgwánéé, 'las candelas de los dioses (de umari)' y los iámè pì:ßénè kúbríguàné 'las candelas de la creación de los animales'.

Cada una de estas categorías se refiere a un repartición de los 'mundos' realizando las venganzas posibles frente a abusos de la parte del individuo o del grupo afectado.

La primera categoría, iñáhi kứhrigwá náßémú, "la candela de los espín ritus del mundo', se refiere a la noción de iñúbì mía múìnáápì 'todos los seres del mundo'. Esta noción relaciona las 'cosas' con sus diferentes dueños. Hemos visto que las plantas curativas tienen sus 'dueños', de igual modo cada elemento materializado tiene su propio 'dueño'. Así, el 'dueño' espiritual forma parte de miá mrioináà pi: 'todos los seres'. El concepto de muinàa áp $t$ está construido con el término de 'gentei, maináa al cual se añade el sufijo/-'ph// que puede ser entendido como singularizador empleado solamente para humanizar. La noción puede ser traducida como 'ser', teniendo omo unos de sus constituyentes una náßéné (plural: nàßémá) un 'espíritu', puesto que no tiene materialización encarnada. Estós múináà pi 'seres son náßémú. Esta categoría se refiere a una dicotomización más general sobre el origen de las cosas. Hay cosas de mé ádjú 'nuestro encima' y otras iñè iñábi 'este mundo'. Las primeras expresan un origen celeste o 'divino', fueron, en cierto modo, creaciones primordiales. El demiurgo las creó en la 'primera tierra' que actualmente es el cielo después que este primer mundo haya sido mandado 'arriba' por una rana mítica quién lo hizo voltear arriba formando así me ádjú. Los actos demiúrgicos dejaron así una mayoría de seres, algunos artefactos, plantas etc, que se pueden encontrar en esta tierra pero con aparencia diferente a la de su origen.

Frente a esta categoría, existe lo que está concebido como teniendo origen en iñè iñúhì 'este mundo'. No forman parte de actos demiúrgicos, pero sí tienen esencia celeste. La persona inspirada queda - después de su desaparición como el responsable de su concepción. Es al nàßénè (espíritu) de ésta a quien se debe ofrecer coca y tabaco para poder hacer uso de su 
concepción. Las enfermedades que se refieren a iñúhì kríhtiqwà nàßémí, "la candela de los espíritus del mundo', son las 'candelas' mandadas por estos naßémù a los que no se hizo ofertas de tabaco y coca antes de utilizar estas wncepciones. Los Miraña dicen que como no se puede conocer a todos estos 'seres' ni a sus realizaciones, se puede pedir al creador de interferir para ellos acerca de estos seres. El mal uso de estos artefactos, de estas planlas así como de las transformaciones operadas sobres estos, pueden provocar la ira de sus espíritus. Aquí también, el trabajo del chamán es de reconocer el origen del que envía la enfermedad.

La caregoría de ni:múémú kriktigwàne 'las candelas de los dioses (o de los umaris)', se refiere a la presentación mítica de unas entidades responsables de estados de pelea, guerra, discordia, expresada en el término de trmékò. Existen así entidades que toman posesión de los seres humanos para poder tener una expresión de sí mismo. Estas entidades, liberando sus 'candelas' e integrando el pensamiento de las personas, están entendidas como trayendo peleas, las cuales, por ser un 'calentamiento' del ser humano, se conciben como una clase de enfermedad. La expresión de esta enfermedad no se hace contra la persona poseída por estas entidades, sino contra su familia que debe soportar la ira del poseido. Estas entidades eran, según los Miraña, muy utilizadas en los tiempos antiguos cuando se peleaba contra otros grupos o contra otras familias. El chamán debía llamarlas para que tomaran posesión de los guerreros. Después de la expedición tenía que hacer todo un trabajo para alejarlas otra vez de los hombres y del grupo en general.

\section{EL 'CURANDERO' Y EL 'BRUJO'}

Estas entidades reciben, hoy en día, su expresión mayor mediante el isikóbe 'el peligroso' o 'brujo' (opuesto al djúúßábe). Este estado es uno de los más peligrosos según los Miraña, porque precipita la víctima en una búsqueda inagotable de enemigos. Pero el estado general del 'brujo' no se reconoce del exterior: no se sabe cuando una persona se vuelve tstikb́bé. 
Mas bien es un estado latente que puede malinterpretar al brujo cualquier acto de los demás como una acción de otros 'brujos' con él. Este personaje, queda también encargado de mandar enfermedades contra otra 'gente', puesto que el djứrßábè no es capaz de hacerlo. Si, para defenderse, este último comete tal acto, es decir si su entorno familiar trata de aniquilar al responsable de la enfermedad en vez de 'enfriarla', él puede a su turno cambiarse en 'brujo'. Desde este momento pierde sus entidades protectoras y se condena a curar 'peleando'. Por eso, dicen los Miraña, existen más 'brujos' que 'curanderos', puesto que todo 'brujo' ha sido previamente 'curandero'. Esta segunda categoría de enfermedad se confunde con las 'maldades' enviadas por los 'brujos' y son concebidas como actos de guerra en contra de un territorio bajo la responsabilidad de un curandero, el cual tiene solamente a su disposición otro brujo para cometer la venganza. Como hemos visto, el acto de venganza no cura la enfermedad, sino solamente da la réplica a la agresión. El acto curativo es esencialmente un acto de 'enfriamiento', razón por la cual el curandero no puede vengarse personalmente, porque tal acto le obligaría a 'calentar' su pensamiento.

Esta dicotomización de los actos chamanísticos ha sido presentada por J.P. Chaumeil (1983, p. 228,229), que indica que el chamán está siempre relacionado al acto guerrero, y que el acto curativo se ubica entre estos actos de agresión y venganzas : "(....) les conflits sont pensés et réalisés dans un contexte d'agression et de vengeance. La conception selon laquelle tout malheur bumain est la conséquence d'agressions magiques, dont l'unique remède est la vengeance, domine de façon permanente la vie des Yagua» (p.228). En el caso del pensamiento Yagua un solo personaje conjuga los papeles de 'brujo' y de curandero, volviéndose restablecedor de orden y al mismo tiempo mandador de maleficio. Aśl, la capacidad de curar está ligada a la de matar: se da y se toma la vida. 




Un curandero (djưtúßábe) Miraña

\section{DIGITALIZADA EN EL CENDOC - CAAAP}


El caso Miraña guarda esta dicotomización fundamental, pero ésta se expresa a través de dos personajes, cada uno tomando un papel único e incompatible. Parece que esta dualidad de papeles está inscrita en la incapacidad otorgada a un brujo o a un curandero a efectuar transformaciones en animales rapińos, para efectuar sus actos de venganzas y/o de mandar por si mismos elementos como dardos u otros que son, dentro del caso Yagua, la materialización de la enfermedad. Pero se piensa también que los brujos tienen como principal medio de enfermedad, preparaciones a base de extractos de árboles que entran en la categoría de pàktúktí é; 'arboles a perfume': olores que tienen la capacidad de penetrar en el cuerpo de las victimas, al igual que los 'olores' de los animales.

Los Miraña actúan siempre con la mediación de entidades diversas puestas al servicio del brujo o del curandero y que se debe retribuir, principalmente, con coca y tabaco o con el alma de la víctima para los brujos y sus entidades rapiñas. Un sistema de pensamiento como el de los Miraña, que atribuye un gran lugar a la comunicación entre espíritus y entidades, debería tener a su disposición una gran variedad de medios de comunicación con estos seres. Los alucinógenos, que podrían ser estos medios y que los Miraña conocen (como kù:riko también llamado 'tabaco de monte': Virola sp.), casi no están en uso actualmente dentro del grupo. La mediación se efectúa mas bien a través de los sueños cuya interpretación es una de las principales vías de comunicación con estas entidades. El otro medio es dar la responsabilidad de los pensamientos de una persona a una entidad. El diálogo 'interno', como está concebido dentro de la cultura occidental, no tiene fundamento en la cultura Miraña. La respuesta del diálogo no está dada por la misma persona, sino por una entidad que la inspira, y doblemente para un brujo o un curandero. Estos especialistas pueden reconocer quienes, de todas las entidades que existen, han sido sus interlocutores durante la noche. Así, el viaje chamanístico descrito en muchos casos etnográficos no existe para los Miraña donde son las entidades mismas que emprenden el viaje hacía el chamán. Estas concepciones tienen que ser relacionadas con la organización social del grupo, donde un 'capitán' tiene a su servicio varios 'encargados' que van a repartir las invitaciones para los 
'bailes' y enviar noticias. Muy pocas veces he visto un capitán dejar mucho tiempo su maloca, y los niveles jerárquicos parecen más marcados aquí que en otros grupos amazónicos.

\section{DOLORES, SUSTOS Y CHACRA}

La totalidad de las enfermedades está así sometida a tres clases de entidades. El origen de la enfermedad queda, de todos modos, en la transgresión, de parte de los humanos, del orden preestablecido. Frente a éste, se desarrolla la ira de los responsables y de las entidades, ira que se manifiesta por la emisión de calores.

Siguiendo las huellas del cucarrón pedómano, existe otro mito donde se presenta unas tantas entidades que, por sus comportamientos, producen afecciones particulares al contraveniente. Este fragmentto que presento ahora, es parte de un mito más largo que relata la creación del tabaco y de la coca. Para los Mirańa este mito forma parte de la fase que es conocida como 'la segunda creación', una de las cuatro creaciones que constituyen la totalidad del proceso demiúrgico. La primera parte del mito relata como el creador se distanció de los humanos, después que ellos ponían en duda la utilidad de los trabajos que hacían. Dentro de estos trabajos figuraba la producción de coca y de tabaco que guardaba exclusivamente para él. El creador se retiró de este mundo, dejando a los humanos sin chacra y sin comida porque se las llevó con él. Frente a este estado de hambre, el hijo y la hija mayor del creador, que se habían quedado a lado de los humanos, trataron de comunicarse con su padre. Durante esta comunicación con el demiurgo, los mayores recibieron la lista de las entidades responsables de los infortunios si los humanos no llevan como se debe el cultivo de la chacra.

1. "Mi tabaco, no es así no más. Mi tabaco lo están cuidando los dueños que yo formé para que cuiden a este tabaco. Le cuento para que usted lo cuente a sus abuelos. ${ }^{36 "}$ Y él empezó a contarle: "Mi tabaco 


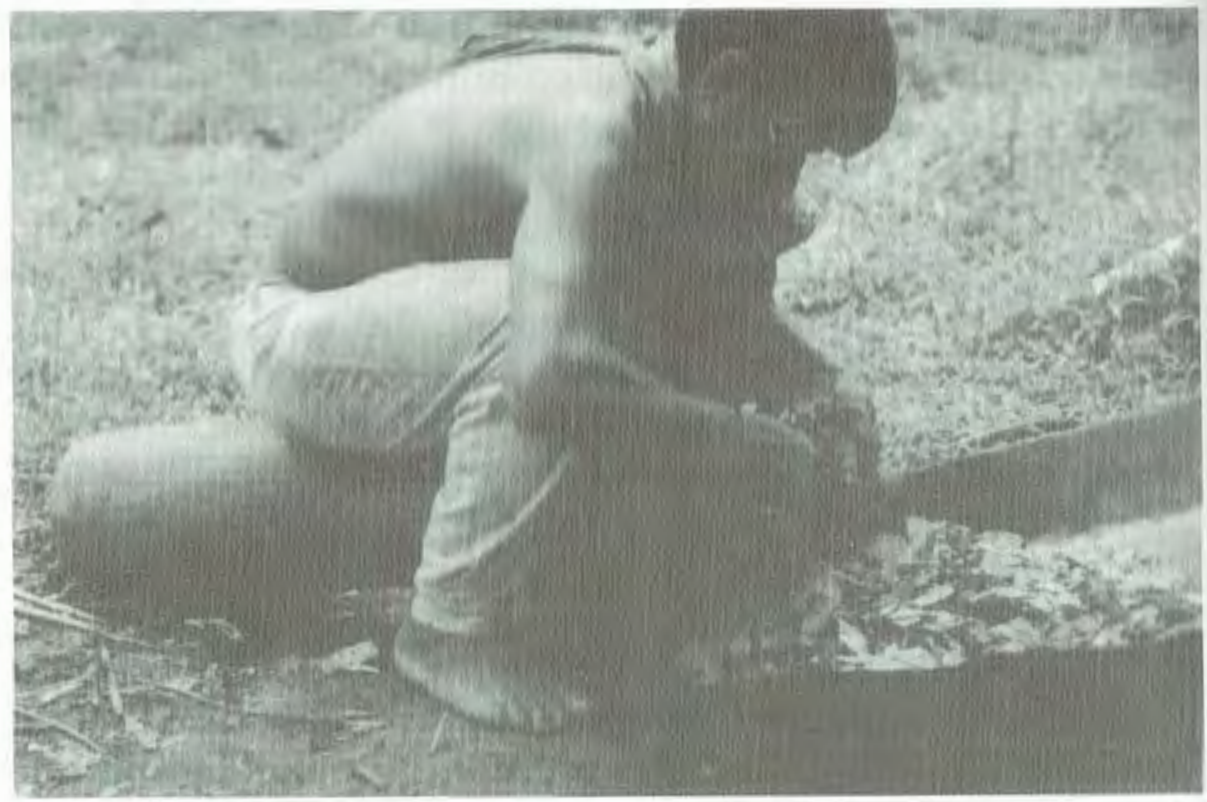

Preparación de las bojas del 'árbol de comida' (coca)

tiene dueños, que asustan, que cuiden. Primero creé a báñéè itšúbà: 'Garza del tabaco'.

* Y a bañéè bóa: 'Anaconda del tabaco', después a los:

* báné è mè:gwámu : 'Gavilanes de tabaco', después a estos, los

* bánè è kìgwámu : 'personales ${ }^{37}$ del tabaco'.

2. Ellos son:

* báñéè gwásà : 'el espiritu malo del tabaco’ que se llama también bàñéè díbè : 'jaguar del tabaco'.

* bàñéè dyú'ktirì : el 'enano del tabaco'.

36 Los "abuelos" son los humanos, que llaman al hijo mayor del creador "nieto".

37 kùgwdmù: literalmente: "los de suefio", que permiten al capitán 'descansar'. 
bànéè má:dảà el 'garzón del tabaco'.

bànéè kiki:hè el 'murciélago del tabaco'.

bànée írò'hirobà: la 'mariposa del tabaco'.

bañéè ini:mé : la 'culebra del tabaco'.

bànéè tšihtši : el 'rayo del tabaco'.

bàñéè núbà el 'sol del tabaco'.

bànéè tíónè : la 'curupira del tabaco'.

bàñe’è mé:z el 'padre de monte del tabaco'.

bàñée tóhtí la 'lombriz del tabaco'.

bàñéè nà:ßénè el 'espíritu del tabaco'.

bànée tà tšibà: el 'gusano sp.? (de color azul) del tabaco'.

bànéè pàgwáhit: la 'araña del tabaco'.

bàñéè buí

bànéè nú:buirtút: el 'bordón del tabaco'.

bànéè námò:kóbi : la 'cucuy (luciérnaga) del tabaco'.

bànéè míkrírigwà: el 'cucuy (luciérnaga) del tabaco' (otra sp., lleva el mismo nombre que 'estrella').

bàñéè néßsưtu: el 'cucarón del árbol de perfume (id?) del tabaco'.



bànéè tyè:ólì : el 'cucarón sp.? del tabaco'.

bànée 'e nòmíbà : el 'cucarón sp.? del tabaco'.

bàñé è bà:bá'ht : el 'cucarón sp.? del tabaco'.

bànéé kì:tyà 'ì : el 'cucarón sp.? del tabaco'.

bàñé ’̀ á:yòbá: el 'cucarón sp.? del tabaco'.

3. Ellos son los que van a cuidar mi tabaco. Y formé los que iban a cuidar mi $\mathrm{coca}^{38}$ :

máhtsótàe itšúbà: Garza del árbol de comida' (de la coca).

máhtsótà è bóà: 'Anaconda del árbol de comida' (de la coca).

máhtsótà 'è mè:gwáhi: 'Gavilán del árbol de comida' (de la coca), así que sus personales. Ellos son los que cuidan mi coca.

Para los 'dioses", la coca no lleva el nombre de $i$ 'bat, pero el de árbol de comida' o 'árbol de provisión': máhtsótà'?. 
4. Después formé los que iban a cuidar mi chacra ${ }^{39}$ : Garza, Anaconda, gavilanes de las comidas, así como a sus personales".

5. El dejó a estos cuidadores como dueños, para que cuidaran lo que él había creado. Pero estos dueños no van a comer la gente si ellos tocan las cosas, por eso él dijo: "No es para comer, ellos no tienen dientes, no hay nada". Pero si al contrario no cuidamos bien estas cosas que nos dejó el creador, entonces ahí sí unos de estos seres pueden asustarnos, la noche, en el sueño. Entonces uno sueña con uno de éstos, él viene en el sueño y lo asusta a uno para que vuelva a cuidar bien estas cosas.

6. "Bueno era para eso, para que usted cuente a sus abuelos", --"bueno!" dijo el hijo, y se fue donde sus abuelos para contarles lo que el padre le había contado. - "Bueno, nieto!" Y él repitió otra vez para que las mujeres cuiden la chacra, la yuca y todo..., diciendo a los hombres de decir a las mujeres de cuidar bien estas cosas porque el creador sabe todo lo que pasa. Y los dueños de estas cosas pueden, por medio de la comida, de la coca o del tabaco, hacerle daño a la gente. Ellos pueden cagar en las comidas, entonces les da vómito y churrea a la gente.

* Los gavilanes: ellos, por medio de la comida, del tabaco o de la coca, le agarran la cabeza con sus garras (eso es dolor de cabeza).

* El alacrán: él puede, por medio de la comida de la coca y del tabaco, chusarle la boca o el estómago de uno.

* Los gusanos cagan en la comida, en la coca o en el tabaco, eso le da rasquiñas al cuerpo de uno.

* La araña, ella le muerde el corazón de uno.

* El jaguar, le masca a uno.

* El anaconda, cuando una persona dice que no tiene aliento, que siente su cuerpo como flojo, ese es el anaconda que le apriera.

* El bordón, pica y produce bordones en los oídos de uno volviéndole loco.

39 Con el sufijo nominal -gwd (que viene del genérico á:ntgwá: "estaca de yuca'): las provisiones o las comidas, e decir: mahtsót td', refiere a todo lo que es la chacra: mathtsótdgwd, fuera de las producciones masculinas como la coca o el tabaco. 
Los námó:kàhì cucuy (luciérnagas), ellos producen rasquiñas. Los mikúrigwà le hacen salir este 'carate'40

Los enanos le hacen como corriente, como cuando le toca un 'temblón'si como un rayo.

El garzón le hace vomitar, produce vómitos, con sus alas. Y lo hace temblar a uno, porque a veces se sacude las alas.

El murciélago lo hace enloquecer a uno y también le produce churrea. Lo enloquece a uno porque él es loco. Lo hace pensar como extraño, con dudas.

La mariposa orina y sacude el polvo de sus alas para darle rasquiñas a uno. Le da fastidio al cuerpo cuando ella orina, todo es por medio de la comida. Vuela con uno, por eso, a veces uno siente el cuerpo como elevado, muy liviano.

La culebra le asusta feamente a uno en los sueños.

El rayo le cae encima de uno y le hace salir dolores en las añaduras de los huesos.

El sol le alumbra y le hace salir calores, le calienta mucho el cuerpo. Pero también le puede hacer doler la cabeza por medio del alumbramiento fuerte que produce.

Los țónémì lo asustan a uno; se presentan en el sueño. A veces él habla en el monte y no hay nadie y la gente busca en vano.

El mé:"í que es el dueño del monte, también trata de asustarle pero con ruido, como si hubiera gente caminando en el monte, o que están tumbando palos. Si es el de la comida, él asusta a las mujeres, si es el de la coca o del tabaco él asusta a los hombres. Es también el que le hace soñar con otras personas para molestarle a uno.

El tátř́ibà, un gusano de color azul, él le asusta a uno, y le truesa el cuero del cuerpo así como él truesa las hojas del tabaco. Cuando él camina encima de uno, se siente como corriente, electricidad, encima de la piel.

\footnotetext{
$40 \quad$ micosis de la piel: pdirn.
$41 \quad$ El término para la anguila

41 El término para la anguila eléctrica es el mismo que para el rayo o el trueno; tsihtst.
} 
* El lombriz le hace salir unos granos en el cuerpo que le quema a uno. Estos producen como quemaduras porque él es el 'lombriz de candela' porque necesitamos candela para hacer la chacra. (Porque antes de hacer la chacra, ellos tienen que aconsejar estos dueños, y después de terminar tienen que desaconsejar. Es que uno está maltratando al monte, entonces con la misma cosa que uno maltrata a los árboles, al monte, estos espíritus le responden a uno).

* Los nà:ßsénè, los espíritus, le asustan también en el sueño o con ruido.

* La garza, el anaconda y el gavilán son los principales; ellos mandan al resto del personal.

* La garza es la que trata de aconsejar a los otros dos: la anaconda y el gavilán. Ella trata de arreglar las cosas. Porque el anaconda y el gavilán siempre hacen algo, siempre están en espera de hacer daño por medio de los personales o por poder propio.

* El cucarón né̉ úxù (cucarón 'comemierda') puede castigar arañando adentro del estómago de uno.

* El cucarón bòródji'o, cucarón del árbol de 'perfume' pàkùkù è, de color brillante entre verde y amarillo. Cuando la dueña de la chargra piensa en cosas como a ir con otro que su marido, como enamorarse con otro varón, este bòródjì̀ se hace muy bonito y por medio del perfume de este mismo árbol la hace pensar en cosas de amor.

* El cucarón $\beta o \beta \delta$ úu, cucarón bronquiador que hace huecos en los huesos de la gente, como cuando él come. Él produce dolores en los huesos.

* El cucarón tyè:íht, que tiene como colmillos, lo muerde a uno. Pero también cuando él orina castigando, en el ojo de uno le produce la ceguera.

* El cucarón nòmíbà, cuando camina encima del cuero de uno, le da fastidio a uno, castigándolo.

* El cucarón bà:bá'bi, donde orina lo quema a uno. Entonces por medio de la comida produce enfermedades.

* El cucarón kì:tyuiu iu, 'el trocedor', así como él truesa a los árboles, también lo truesa a uno. Se dice que truesa al cuerpo de uno. 
El cucarón á:yòbá, se encuentra en la chacra, él es miedoso porque tiene unos ojotes. Él come las hojas de yuca pero no le muerde a uno, él lo asusta no más.

* El gusano màhtšótà tsò:gwátì, 'tsó:gwà̀ de la comida', él vive en la yuca y en el ñame y de la misma manera come los tubérculos como la carne de uno. Uno siente dolores como si él estuviera comiéndole a uno.

* El gusano màhtsótà b:nóbà, vive en la chacra. Él está para cuidar a la semilla de yuca, o de las comidas, si no se cuida, hace podrir la semillas.

* El gusano màhtsótà áhtsígwà, vive en el tronco de los palos, y alumbra de noche. Cuando él castiga, produce enfermedad, poniendo candela adentro de uno.

* El gusano màhtšótà nidjtłbà, hace lo mismo que el otro, pone candela en el cuerpo de uno, el también alumbra de noche.

* El cucarón escarbador màhtsótà bó djajò, él castiga escarbando el cuerpo de uno como hace en las chacras cuando escarba la tierra volviéndola polvo.

Después vienen los que ayudan para el trabajo de la chacra.

* El pájaro màhtsóotà tsìrékóbó, él silba para dar aliento a las comidas, para que crezcan.

* El oso hormiguero pequeño ${ }^{42}$ màhtósotà t'tha, ayuda a los que quieren sembrar rapido, él les ayuda rompiendo monte y abriendo huecos.

* El espíritu malo del 'armadillo trueno': mahtsota nidj mit3 él ayuda a abrir huecos para sembrar, porque sin miedo va abriendo huecos en la tierra.

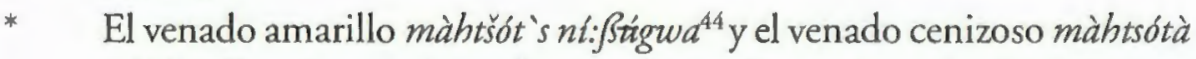
$i: b d^{45}$ ellos dos son los palos con los cuales se abren los huecos para

f'thi: Cyclopes didactilus.

nidjim: Priodontes maximus

ni Pugwa: Mazama americana

l:bà: Mazama gouazoubira 
sembrar. El largo es el venado amarillo y el mediano es el venado cenizoso. Como ellos corren rápido se nombran para terminar el trabajo rapidamente.

* El murciélago máhtšóta nò: étu, cuando se piensa con este espiritu, puede ser una chacra muy grande, pero tan rápido como cierra su boca, está sembrada la chacra.

* La danta màhtšota ókáhi, este espíritu, donde camina, hace rastros grandes. Entonces uno piensa con este espíritu para que dé yuca grande.

* El oso hormiguero màhtšóta tyo htít, él es el dueño de las comidas porque se le pide: «suelta sus provisiones para nosotros, para que la chacra dé mucho".

* El pájaro mahtsota ko:iri, canta para que las comidas se queden contentas, para que crezcan sin dificultad y sin enfermedades. Él les habla, sacudiendo las maticas para que no quede mugre encima.

* La 'mujer rana' máhtšótá káká mé:gwà, ella es la dueña de las comidas, para que las comidas crezcan sin que se les añada candela. Ella queda también para que la comida tenga mucho almidón.

* La 'mujer hormiga 'konga'47 de las comidas màhtšótá á:nútu me:gwa, esta hormiga, esta mujer, tiene su carga en un canasto. Así como ella carga su comida, uno carga las comidas de la chacra. Los nietos de esa mujer, que son las hormigas á:nuitu, se encargan de picarle el cuerpo de uno castigándole.

* La chichara màhtsótá tsí: "èdò, cuando ella vuela y que le toca el cuerpo de uno produce como corriente y le asusta a uno.

* La chichara pequeña mahtsota ryìryito canta para que se alegre la vida de las comidas.

8. (Toda esta gente, estos 'espíritus' fueron creados por el creador. Todo eso porque, cuando se hace una chacra, si no se pide permiso antes, y se maltrata a los árboles, al monte, entonces estos espíritus respon-

46 tyo hr: Tamandua tetradactyla

47 a: núr. Grandiponera spp.? 
den de la misma manera. Pero si se pide permiso antes al creador, y si se le da coca y tabaco, él puede aconsejar a sus espíritus para que ellos no les respondan a uno. La misma cosa, la misma gente existe también para los animales, pero son de ìámè báñe $e^{48}$, eso viene de la creación de los animales. Existe también esta misma gente que son de los árboles de perfume pàkìkù émù de lo cuales se prepara las 'pusangas' que usan los brujos para enfermarlo a uno.

9. El curador debe encontrar cual de estos espíritus está maltratando a esta persona. Todo eso, espiritualmente. Eso se enseña a la edad de 10-13 años, para que los niños sepan cuidar las comidas de la chacra. De toda esta gente vienen las enfermedades de la comida, las candelas de la comida.

10. El hijo estaba diciendo que se tenía que aconsejar estos espíritus: «después se puede sembrar»-«Bueno, nieto» respondieron los abuelos.-«Mañana vamos a sembrar, descansen» $Y$ se fueron a descansar. Y se volteó al lado del papá de él diciendo: "cómo está lo que comenté a mis abuelos, de lo que usted me ha dicho?»-«Está bien, porque no hice estas cosas así no más, eso tiene dueño. Si ellos lo cuidan no les pasará nada, en cambio si no cuidan bien, si no obedecen, así, les pasará algo, a ellos no, pero a los que siguen, ellos les va a pasar algo»"Bueno", respondió el hijo.

11. (Eso es lo que les va a pasar. Por eso es que nos pasa todo eso ahora. Pagamos lo que hicieron nuestros abuelos. Porque lo dijo así en ese tiempo. Por eso hacemos estas cosas, coca, tabaco, manicuera, porque él lo dijo así.)

12. En eso el padre enfrió todo lo que era níba kríhrígwà 'calor del sol' y úmí è kúhùgwànè 'calores de la chacra' ${ }^{349}$. El enfrió todo. ${ }^{50}(. .) .$.

El alucinógeno Virola ssp.

Evocación de las diferentes entidades presentadas más arriba.

En la noche que precede la sembra de una chacra, el curandero debe comunicarse con el creador para que él siembre el árbol kúdjè è (un Anonacae) al centro de la chacra para que produzca sombra a toda la chacra y al agente que van a trabajar en ella. Así ni el sol, ni las otras entidades responsables de las enfermedades, "queman" la gente. 


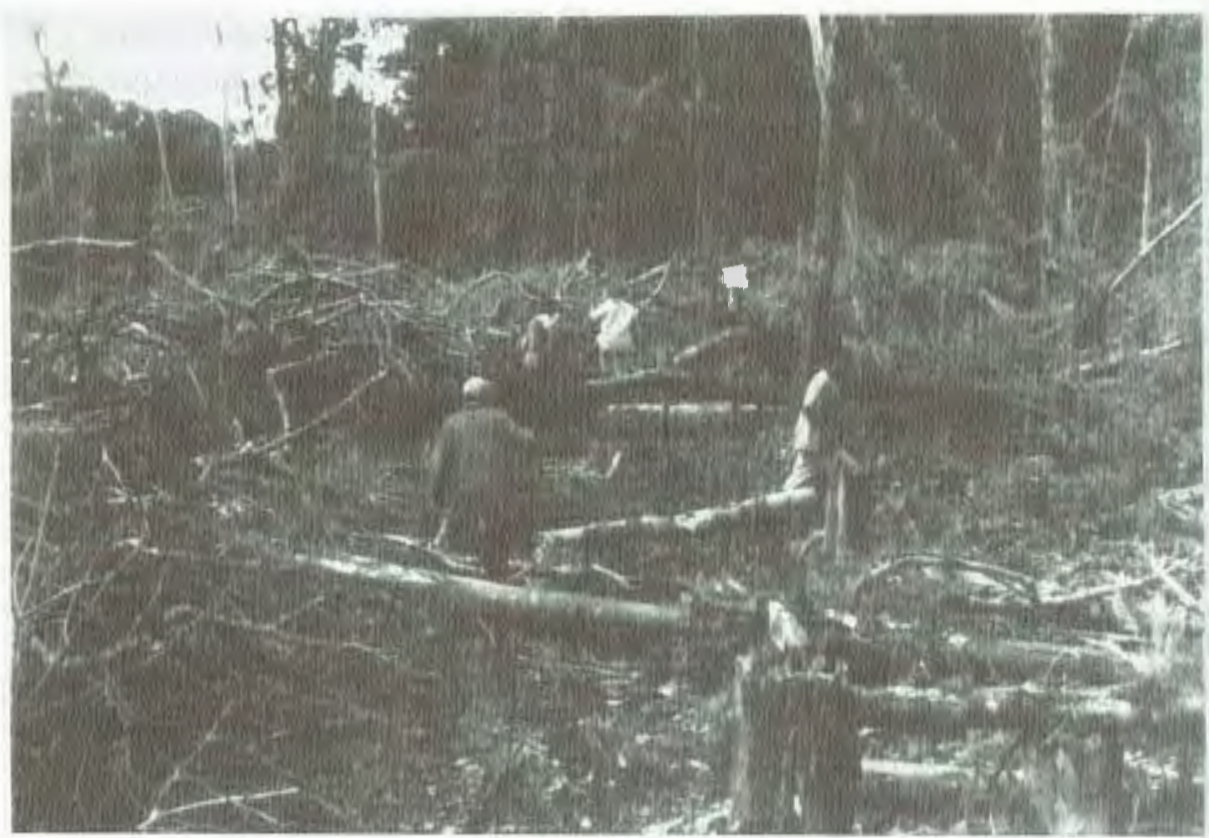

El campo de los árboles muertos.

El mito sigue con los diferentes trabajos del cultivo de la chacra, hasta que los humanos aprenden todo de la boca del hijo y de la hija mayor del creador.

La parte del mito presentada enumera las diferentes entidades que producen las enfermedades humanas. Muchas de las explicaciones dadas por el narrador son suficientemente explícitas para no necesitar un comentario. Esta 'lista', que según el narrador puede ser incompleta, puesto que no se conoce todas las creaciones del demiurgo, guarda la tripartición de las enfermedades presentada más arriba. Existen enfermedades 'de la chargra', 'de los animales' y 'de los brujos'. La tripartición presenta cada parte como un universo donde se encuentra las mismas entidades pero con medios de enfermedades muy variables. O se trata de productos de la chacra, o son animales o se trata de «olores» producidos por el brujo. 
La enfermedad pasa por la ingestión de 'alimentos' contaminados por estos 'calores'. En cierto modo se puede decir que los Miraña piensan que todas las especies, consideradas como 'gente', están bajo la responsabilidad de un dueño. Del mismo modo todas las especies son potencialmente transmisoras de enfermedades, no tanto porque contiene substancias nocivas, sino porque son la propiedad del demiúrgico, con la notable excepción de una parte de los animales de caza que tiene su propio 'olor', es decir el almizcle así como algunas especies de peces dotados de dardos envenenados -otros tipo de 'olor'-. Pero, como dice el narrador: «eso es aparte», en el sentido que no son producciones demiúrgicas. Estas especies tienen una independencia propia que necesita un intercambio particular con sus dueños o, como ocurre muchas veces, ningún intercambio. El acto de predación es estonces total, cerca de como se piensa el acto de guerra. La confrontacion es de 'olor' contra 'olor', de veneno contra veneno, de muertos contra muertos.

Las entidades responsables de cada enfermedad forman la base de la nosologia local. Las enfermedades son concebidas como agresiones y los dolores son materializados bajo la forma de insectos y gusanos quienes para los Miraña, son solamente una de las dos materializaciones (la otra sería efectivamente el infortunio) y puede ser entendidos como enfermedades 'internas'. La etología atribuida a estos animales los presenta como haciendo sus daños dentro de los tubérculos, de los troncos o de la tierra. Estos 'escarbadores', 'trocedores', 'broquiadores' son utilizados como metáforas para expresar una estrecha relacion entre el cuerpo humano y la chacra. Afuera de los dolores externos, ninguna de las especies presentadas es estrictamente del monte. Diciéndolo de otro modo, las entidades que producen dolores internos tienen representantes encarnados estrictamente en el dominio de la chacra. El mito presenta de la misma manera las entidades responsables de los dolores corporales y las entidades responsables del desarrollo de las producciones agrícolas, así como las etapas de apertura de una chacra. El paralelo entre constitución del cuerpo y constitución del medio cultivado está marcado por esta relación a la enfermedad. Este paralelismo no se establece tanto sobre las etapas de la constitución corporal, sino más 
bien sobre la equivalencia que existe entre la producción de la chacra y lo que realizan estos productos al ingerirlos: el cuerpo humano.

La relación metonómica entre el cuerpo y la chacra puede ser entendida como un cultivo de la chacra por el hombre, pero con esta particularidad que los cultivos son una transformación de un cuerpo demiúrgico. Maltratar a las especies de la chacra es como maltratar al demiúrgo mismo quien, a su turno, maltratará el cuerpo del ser humano mediante los seres responsables de cada cultígeno. Este paralelismo presentado en el mito entre la chacra y el cuerpo humano es posible porque la chacra está pensada como una transformación del cuerpo demiúrgico. La relación opuesta e inversa de ésta es de considerar que el cuerpo humano está visto por el demiúrgo como una chacra donde él puede hacer intervenir las entidades que van a hacer sufrir al infractor, así como lo presenta el mito. El acto de cultivar es entonces un acto de reconstitución del demiúrgo en su versión vegetal. La chacra es un microteos.

Algunas de estas entidades responsables no tiene ningún representante en la clasificación cientifica de las especies. Assí, los t̀ónèmutú 'currupiras', los nà 'Sénè 'espiritus', el dyu' kúrì el 'enano' y el mè:í 'dueño del monte', son seres estrictamente fantasmáticos, puesto que para los Miraña no tienen apariencia física, pero sí tienen presencia en el monte. Aunque no se puede precisar su aspecto, son los únicos de la lista que llevan un carácter eminentemente antropómorfo. Se puede notar que la acción de estos seres sobre los humanos es principalmente una acción 'mental'. Ellos no producen malestares corporales sino que penetran en los sueños para asustar a la víctima. Entre dolores internos y sustos se puede guardar una interpretación materialista de las acciones de las entidades: donde se encuentre carne o huesos - una base 'material'- las entidades dañinas tienen una personificación en las especies animales. Donde no existe esta encarnación, en el dominio del sueño o en la actitud sicológica del paciente, los agentes responsables no tienen una expresión 'material' como seres. Los Miraña son concientes de que no se ven estos seres, y ponen en duda hasta el hecho de su existencia física. En cambio, las manifestaciones de estos seres son reales 
porque se encuentran en los sueños, y se escuchan en el monte. Son más descritos como una 'voz' que como una materialización hecha de carne y huesos. Esta descripción de la inmaterialidad de estos seres puede guardarse para definir la concepción Miraña del sueño: existe como experiencia, pero no tiene materialización.

Se presentan sin embargo dos excepciones a esta asociación entre los seres imaginarios y el dominio del susto: la culebra venenosa y una especie de cucarrón llamado á:yòbá. Estas dos entidades, también responsables de los sustos en los sueños, se oponen a la asociación evocada, puesto que se pueden encontrar encarnados en el mundo de las chacras. Estas excepciones son más a entender como presencias en el sueño que no se pueden interpretar de otra forma que asociándolas a unos gustos puesto que no están en acción dinámica con otras especies animales o con si mismo. En otros términos, están en una actitud de pasividad con el soñador. La interpretación general de los sueños por los Miraña los presentan como actos premonitorios, debidos al espíritu de cada uno que, por este medio, le avisa de los eventos que van a suceder. Los sueños presentan entonces acciones dinámicas, donde la personificación animal es solamente una marca de las intenciones de los vecinos o de cualquier persona que va a visitar de día al soñador. Por ejemplo, soñar con un jaguar persiguiéndole se interpreta como un gran peligro, porque quiere decir que alguien está tratando de hacer una acción mortífera contra uno. Al contrario, soñar que alguién está matando a otros indica que la caza del día siguiente será prolífera. Existen sueños con frutas y cultivos de la chacra que son interpretados como animales que el soñador va a cazar al día siguiente y que pertenecen a la categoría de animales «sin olores», resultando de unas transformaciones de los productos de la chacra del demiurgo. Los sueños que presentan acciones mortíferas en contra de otros humanos se interpretan únicamente como un encuentro de animales con pàkrikì, con almizcle. Ellos son los únicos que pueden ser entendidos como equivalentes a los humanos, porque tienen este olor que es un equivalente del curare humano. Los 'olores' presentados más arriba son entonces mortiferos porque son interpretados como una clase de veneno que producen 'calores' al origen de la enfermedad. 
La presencia de una entidad aislada en el sueño, que no actúa contra otro animal o contra otra persona, se interpreta como dirigida contra actuaciones de uno en el nivel de comportamiento cotidiano. Más allá del hecho que la mayoría de los seres que producen sustos son antropomorfos: se puede guardar como marco principal de las fobias en el sueño la pasividad de las entidades, frente a la dinámica de los actores en el sueño premonitorio (que no es un agente patógeno). Para expresarlo de otra manera, la dinámica del susto en el sueño está dirigida contra uno, y se interpreta por los Miraña en la pasividad del soñador al encontrarse con seres antropomorfos.

Así, la acción de cultivar es una acción trasladada sobre si misma: los hombres por medio de sus producciones, coca y tabaco, las mujeres por medio del resto de los cultivos. Se cultiva la salud como se cultiva la chacra y esta relación no es solamente una expresión metonímica en el pensamiento Miraña: existe un vínculo encarnizado entre los dos dominios. Los dolores y sus agentes responsables existen para que se recuerde este víncullo.

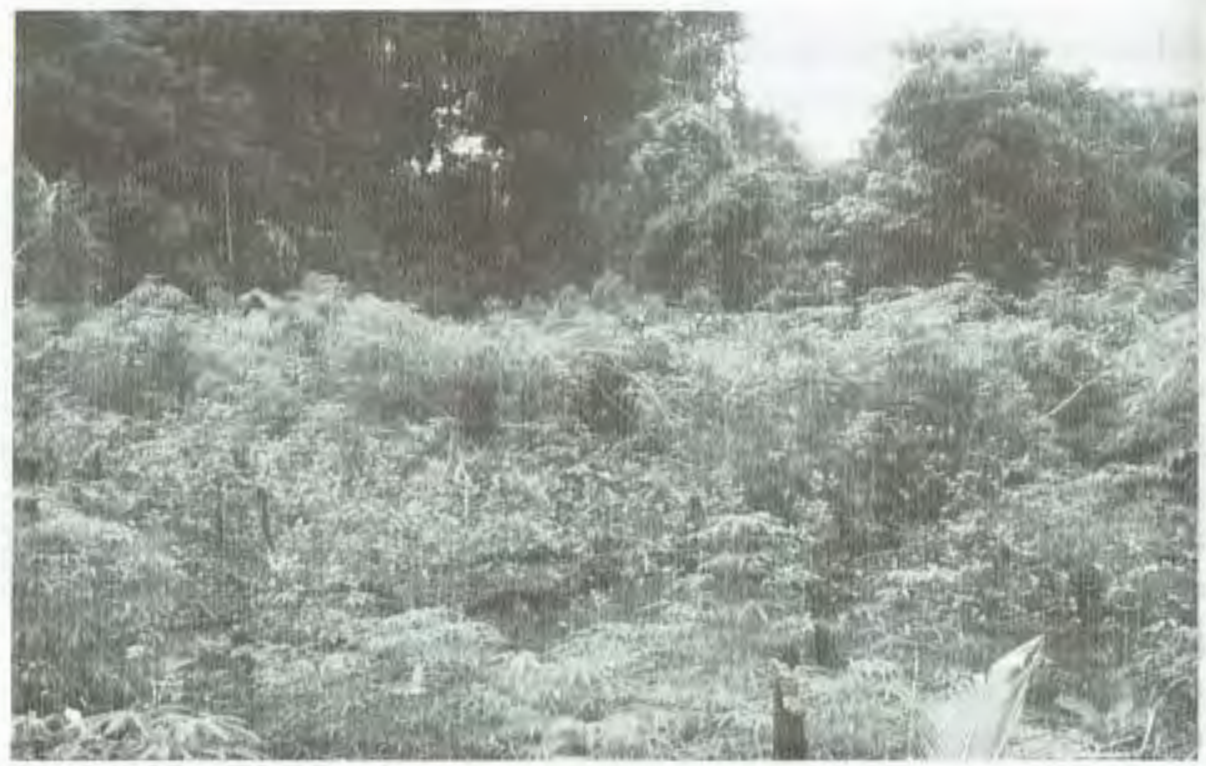

La chacra: un microteos. 


\section{CONCLUSIÓN}

Entre 'olor' y 'calor', la actitud general de los Miraña frente a la enfermedad es entonces principalmente el resultado de transgresiones humanas al orden establecido. Pero presentar la enfermedad como un estado que podría evitarse por un buen comportamiento, y mostrar que la vida podría seguir hasta su fin sin ella, sería traicionar el pensamiento Miraña. Esta idea presentaría la muerte como un escatón, como una finalidad. La muerte "de vejez», o una «buena muerte» es seguramente una idea alejada del pensamiento de esta etnia. Así, aunque el comportamiento individual puede ser lo más respetuoso, siempre quedarían los grupos vecinos o los animales de 'olor' para tratar de vencer a la persona o al zi'etè de algún Miraña. Las respuestas deben ser producidas para no quedar como víccima de tales actos; respuesta individual dirigida hacia el reino animal, respuesta del especialista en contra de los grupos vecinos. El acto curativo, disociado del acto dañino, está llevado por un especialista que trata de restablecer la normalidad por la restitución del nivel isotérmico del paciente, o para tratar de cambiar el 'olor' responsable del estado de malestar.

En el estado de infortunio, caracterizado por dolores corporales atribuidos a entidades responsables de la chacra, la asociación está principalmente basada en la clasificación de este dominio desprovisto de 'olores', excepto en el caso de la yuca brava que posee su propio veneno, metaforización vegetal de la sangre menstrual. El estado de infortunio no se traduce en términos de 'olores' y por tal razón no tiene fuerza letal. No constituye una categoría marcada terminológicamente y se puede disociar de las enfermedades ya que no tiene el mismo origen ni la misma respuesta terapeútica.

Sin embargo, el caso Miraña presenta una actitud general a los estados de infortunio y de enfermedad y frente al acto terapeutico: esta actitud común está basada sobre la noción de intercambio con los seres y los elementos, como con las entidades fantasmáticas. El medio por el cual se realiza este intercambio, es la producción de cada uno: los hombres deben 
'mambiar' coca dedicándola a las entidades responsables, y las mujeres deben preparar caldo de yuca dulce y casabe pensando en estas mismas entidades. Las nociones de 'frío' y de 'caliente' a las cuales se deben añadir las de 'dulce' y 'picante', son una categorización que les permiten concebir la totalidad de las relaciones, que sean interpersonales -sociales-, inter-especies tróficas -, o, inter-mundos - religiosas -. Este intercambio se realiza, para los Miraña, a través de las producciones de 'dueños', materializados por animales, frutos y plantas. Al centro de todas estas concepciones queda el imaginario del cuerpo, que sea humano, animal, vegetal, demiúrgico o cósmico. En cada uno de estos dominios se debe encontrar un elemento constituyente del todo. Así, la enfermedad, lejos de limitarse al dominio humano, es una categoría pertinente para expresar desórdenes particulares a cada dominio. El modo de entenderla es, para los Miraña, la experiencia sobre sus propios actos productivos; progenie, cultivo, caza, artefactos, palabras... El modo de curar las enfermedades, de 'enfriarlas', es tanto en realizar actos profilácticos, para que no tengan modo de expresión, como en actos terapeuticos, restablecedores del orden.

Del 'olor' al 'calor', aquí queda la noción de enfermedad, pero no incluye el acto mortífero que está pensado como un acto caníbal: para morir, el principio vital debe ser dóo' '̇'devorado', (o 'comer carne') por unos seres viviendo en mè ádjù "nuestro encima". Esta devoración se materializa por el ruido del trueno que es la masticación del alma por estos seres. Pero cualquier acto de devoración en esta tierra es equivalente. Como dicen los Miraña, "uno no se muere de enfermedad, el que mata es el que come". Así la enfermedad es solamente lo que debilita a la persona, a la sangre, y deja así salir su alma. Los espíritus aliados del curandero tratan de recuperar esta alma antes su devoración. 


\section{BIBLIOGRAFIA}

CAYCEDO, G.

1985 Perdido en el Amazonas, Bogotá: P \& J eds, (1 ra. Ed., 1978).

CHAUMEIL, J.P.

1983 Voir, Savoir, Pouvoir. Le chamanisme chez les Yagua du Nord-Est péruvien. Paris, Ed. de l'E.H.E.S.S., 352 p.

ETCHEVERRI, A.

1993 Tabaco frío, Coca dulce. Obra presentada al Premio Nacional al Rescate de la Tradición Oral, Colcultura, manuscrito.

GUYOT, $M$.

1975 "Le système cultural Bora-Miraña", en Culture sur brulis et évolution du milieu forestier en Amazonie du Nort-Ouest. Bul Schweiz. Ethnol. Ges. Sondernumer, Genf.

HUGH-JONES, Ch.

1979 From the Milk River: Spatial and Temporal Process in Northwest Amazonia. Cambridge, Cambridge University Press, 302 p.

JACOPIN, P. Y.

1981 La Parole Générative. De la mythologie des indiens Yukuna. P. Lepettit, Tremlay, 389 p.

KARADIMAS, D.

1992 "Il Corpo Bora-Miraña: ideología a rappresentazione", en Corpi a Confronto, a cura di F. Lupu \& G. Della Gagione, Dipartimento di Scienze Glottoetnologiche, Universitá di Genova, pp. 111-121.

LANDABURU, J. \& PINEDA, R.

1984 Tradiciones de la Gente del Hacha. Mitología de los indios andoques del amazonas. Caro y Cuervo, UNESCO, 289 p. 
LAROTTA, C.

Especies utilizadas por la comunidad Miraña. Estudio etnobotánico. FEN-Colombia, WWF, sin fecha, $381 \mathrm{p}$.

LÉVI-STRAUSS, C.

1985 La potière jalouse. Plon, Paris, 314 p.

PREUSS, K. Th.

1921 Religion und mythologie der Uitoto. Vandenhoeck \& Ruprecht, Göttingen, 12 Bände.

REICHEL, E.

1989 "La danta y el delfin: manejo ambiental e intercambio entre dueños de malocas y chamanes. El caso Yukuna-Matapi (Amazonas)" en, Revista de Antropología, Vol. V, nº 1-2, Bogotá, Universidad de los Andes.

SPIX, J. B. \& VON MARTIUS, C.F. Ph.

1980 Reisen in Brasilien in den Jahren 1817-1820. Brockhaus Komm.Gesch. GmbH., Abt. Antiquarium, Stuttgart. (1era. Ed., 1831), 3 Bände.

URBINA, F.

1992 Las hojas del poder. Ed. Universidad Nacional de colombia, Bogotá.

VAN DER HAMMEN, M.C.

1992 El manejo del mundo. Naturaleza y sociedad entre los Yukuna de la Amazonía colombiana. Ed. Tropenbos Colombia, Colombia, 376 p. 